\title{
Quem está no comando? Mulher de bandido e os paradoxos da submissão
}

\author{
Sabrina Daiana Cúnico' (iD) 0000-0003-2198-9957 \\ Marlene Neves Strey2 (iD 0000-0003-3030-5668 \\ Angelo Brandelli Costa ${ }^{2}$ (D) 0000-0002-0742-8152 \\ 'Universidade Feevale, Novo Hamburgo, RS, Brasil. 93525-075 \\ 2Pontifícia Universidade Católica do Rio Grande do Sul, Porto Alegre, RS, Brasil.
}

90619-900

\section{$-$}

Resumo: Este estudo teve por objetivo discutir qual o modelo de família que é produzido nos discursos e práticas de mulheres que têm relações afetivas ou sexuais com homens que estão em situação de prisão, a partir de uma análise do feminismo interseccional e do estudo do biopoder. Por meio de observações participantes com mulheres que visitam seus familiares, foi possível identificar que o modelo de família produzido ainda é sustentado pelo modelo hegemônico tradicional, que entende a família nuclear como a representação do sucesso e solidez familiar. Tal ideal de família opera através da reprodução de certas normas e papéis sociais assumidas pelas mulheres, tendo-paradoxalmente - um certo caráter empoderador.

Palavras-chave: família; mulher; prisão; biopoder; interseccionalidade

Who's in Charge? Wives of Criminals and The Submission Paradoxes

Abstract: This study aimed to discuss which is the family model produced in the discourses and practices of women who have affective or sexual relationships with men who are in prison, based on an analysis of intersectional feminism and the study of biopower. Through participant observations with women who visit their relatives in a male penal institution, it was possible to identify that the family model which is produced is still supported by the traditional hegemonic model, which sees the nuclear family as the representation of success and family consistency. Such family ideals operate through the reproduction of certain norms and social roles assumed by women, having - paradoxically - a certain empowering character.

Keywords: Family; Woman; Prison; Biopower; Intersectionality

\section{Introdução}

De acordo com a Lei de Execuções Penais (LEP), datada de 1984, todos os indivíduos privados de liberdade possuem direito a receber visitas de seus familiares. Todavia, não há nenhuma menção na lei sobre a possibilidade de encontros íntimos entre os presos e visitantes (BRASIL, 1984), muito embora se pressuponha que tais encontros sempre aconteceram. A visita íntima só foi regulamentada em 1999, pela Resolução $n^{\circ} 01$ do Conselho Nacional de Política Criminal e Penitenciária do Ministério da Justiça (CNPCP), a qual recomenda que "seja assegurado o direito à visita íntima aos presos de ambos os sexos, recolhidos aos estabelecimentos prisionais, estabelecendo regras para a concessão do benefício" (BRASIL, 1999).

No Rio Grande do Sul, foi a portaria 004/2001 da Superintendência de Serviços Penitenciários que estipulou as determinações da visita íntima nas prisões do estado (Fernanda BASSANI, 2011). No entanto, em grande parte das prisões brasileiras, em função da superlotação e da falta de um espaço específico para esse fim, as visitas íntimas geralmente acontecem nas próprias celas, sendo a sua organização comandada pelos próprios presos, o que facilita os encontros íntimos. 
Estudos sobre a realidade do cárcere indicam que, quando da prisão de seus familiares homens presos, as mulheres frequentemente assumem para si a responsabilidade de acompanhálos ao longo do cumprimento da pena (BASSANI, 201 1; Helena Salgueiro LERMEN, 2015). Tal situação não se repete quando são elas que estão privadas de liberdade. De acordo com os últimos dados disponíveis pelo Ministério da Justiça, $62 \%$ das mulheres não recebem nenhum tipo de visita na prisão e $90 \%$ não recebem visitas íntimas (BRASIL, 2008), evidenciando o frequente abandono vivenciado por elas, especialmente pelos seus parceiros/companheiros.

A representação que vincula a mulher ao cuidado é algo que se inicia desde a mais tenra infância nas brincadeiras em que são estimuladas a cuidar da casa, dos filhos e do marido. Tais ensinamentos são passados como atividades normais das mulheres para as meninas, sendo naturalizadas como práticas femininas. Nesse contexto, a realidade que se constrói é a de comportamentos estereotipados em que as mulheres são vistas como essencialmente cuidadoras, ao passo que os homens são tidos como pessoas a serem cuidadas (Elisabeth BADINTER, 1985; Jorge LYRA et al. , 2008).

Cada sociedade estabelece normas e modelos do que entende como sendo adequado ao comportamento de homens e mulheres; são os chamados estereótipos de gênero. Um estereótipo pode ser compreendido como algo cultural, historicamente construído, e que pode implicar a dominação daquele que é o objeto do estigma social pelo outro que é o discriminador. É formado por uma série de características fixas atreladas a um objeto e que, geralmente, não se desfazem mesmo quando a experiência prova o contrário (José Leon CROCHIK, 1996).

Na nossa sociedade, os estereótipos de gênero ainda posicionam as mulheres como passivas, frágeis e dóceis. Ao homem, em contrapartida, é esperado um comportamento autoritário, impositivo e agressivo. Tais características se imbricam na teia complexa das relações familiares, produzindo comportamentos estereotipados também dentro da família. Historicamente, o homem, tido como mais forte e vigoroso, passou a ocupar o lugar de provedor, tendo destaque no espaço público. A mulher, por sua vez, vista como frágil e mais disposta a abnegar de seus desejos pessoais, foi tida como a principal cuidadora, ficando relegada ao espaço privado do lar (Martha Giudice NARVAZ; Silvia Helena KOLLER, 2006a).

Traçando uma linha histórica a respeito das formas de organização familiares, é possível identificar que, em função de interesses econômicos vinculados ao surgimento da propriedade privada, outras configurações familiares não monogâmicas foram substituídas pelo ideal de família exclusivamente monogâmica. A partir dessa organização familiar, a divisão do trabalho e dos papéis sexuais e sociais foi sendo delineada. Tendo em vista a preocupação em garantir herança aos filhos legítimos, a virgindade e a fidelidade da mulher passaram a ser valorizadas, momento em que as mulheres passaram a ter seus corpos e sua sexualidade controladas. O chefe - homem da casa - mantinha sobre o seu poder a mulher, os filhos e os escravos (NARVAZ; KOLLER, 2006a; 2006b).

Com o advento do capitalismo, um novo modelo de família emergiu. Nessa nova configuração - a família nuclear burguesa - o homem não era mais o proprietário, mas sim o pai, cuja função era a de mantenedor da esposa e dos filhos. A mulher, não mais propriedade do marido, assumiu a função de mãe, sendo responsável pela educação e proteção dos filhos, bem como pelo cuidado do marido e da casa. Neste panorama, a suposta natureza passiva e frágil da mulher foi utilizada como justificativa para o domínio masculino (NARVAZ; KOLLER, 2006a; 2006b).

É resgatando a historicidade das formas de organização familiares que a família se inscreve na pauta da agenda feminista. Isso porque, ainda que em configurações diversas, ela pode ser considerada como lócus de controle das mulheres, situando-as, a partir de discursos normativos, em posições de subalternidade. É fato que os papéis de gênero provenientes dessas construções históricas vinculam as mulheres como, prioritariamente, esposas e mães, deixando intocado e impossibilitando o protagonismo feminino em outras esferas da vida. No caso das mulheres de classes populares - incluindo aqui as mulheres que têm relações afetivas ou sexuais com homens presos -, acrescentam-se as dificuldades enfrentadas pelo simples fato de ser mulher, o ônus da baixa escolaridade, das escassas oportunidades de trabalho e, para muitas, a discriminação racial (Cristian Fabiano GUIMARÃES et al., 2006) e a discriminação por ser companheira de um homem preso.

O conceito de interseccionalidade ganhou destaque ao final da década de 1990 juntamente com a emergência de diversas categorias identitárias que aludem à multiplicidade de diferenciações que, aliando-se ao gênero, transpassam o social, tais como raça e classe, por exemplo. Sendo o gênero uma forma de opressão, como explicar as diferentes opressões vividas pelas mulheres negras, de baixa renda, lésbicas? A explicação reside justamente no reconhecimento de que existem outros sistemas sociais que se intersectam com a questão de gênero e que são fatores simultâneos de opressão. Assim sendo, analisar algum fenômeno à luz da interseccionalidade é assumir que raça, gênero, classe e sexualidade não existem isoladamente um do outro. Tais categorias existem em e por meio da relação estabelecida entre elas (João Manuel OLIVEIRA, 2010; Adriana PISCITELLI, 2008; Verena STOLCKE, 2014). 
É nesse contexto que argumentamos que não é possível compreender de forma segmentada os mecanismos de exclusão envolvidos nessa intersecção entre vários planos de opressão (OLIVEIRA, 2010). Em outras palavras, é fato dizer que as experiências das mulheres que frequentam o espaço da prisão são determinadas pelo seu posicionamento social mais amplo. Isso significa considerar que essas mulheres são, em grande parte, pobres, negras e com histórias de vida marcadas por privações estruturais marcantes (Mariana BARCINSKI; Carine CAPRA-RAMOS; João WEBER; Tamires DARTORA, 2013).

Ao estudar famílias de classes populares, Vannuzia Leal Andrade PERES (1997) identificou que estas famílias eram frequentemente chefiadas por mulheres que desempenhavam um papel central na manutenção da rotina da casa e na educação dos filhos, sendo que grande parte destas famílias era proveniente de uma gravidez precoce ou não planejada, instabilidade familiar e/ou abandono (Rosa Maria Ferreira PINTO et al., 201 1). À parte das transformações vivenciadas pela família contemporânea, nestas famílias os valores tradicionais que vinculam o homem como sendo o mediador entre a família e o mundo externo ainda persistiam, reforçando os estereótipos associados à autoridade masculina (Cynthia A. SARTI, 1994).

Ademais, muito embora a situação concreta dessas famílias se afaste do modelo idealizado nuclear burguês - especialmente devido à ausência do pai no ambiente familiar - ela também legitima tal configuração como sendo a ideal, assumindo para muitas destas mães a condição de família modelo, aquela que é buscada e desejada (Sabrina Daiana CúNICO; Dorian Mônica ARPINI, 2014; NARVAZ; KOLLER, 2006a; PERES, 2001). Transpassando esta discussão para o contexto prisional, é possível conjecturar que, para muitas mulheres, o fato de engravidar de um homem privado de liberdade está relacionado com a ideia de que um filho confere certa solidez para as relações afetivas, marcadas pela ausência do companheiro. Ausência esta que, segundo Sarti (1994), fragiliza socialmente aquelas famílias em que não há um homem no papel de provedor.

É nesta perspectiva que Pierre BOURDIEU $(2008$, p. 135) situa a família como sendo "uma ilusão bem fundamentada", o que faz com que seja buscada e idealizada. No entanto, o autor pontua que a família nuclear heterossexual pode ser considerada um privilégio que foi instaurado como norma universal. Um privilégio também simbólico na medida em que constituir uma família na configuração nuclear traria como consequência o lucro simbólico da normalidade.

Essa situação remonta a uma concepção de família que legitima valores tipicamente burgueses e que se mostra uma ferramenta potente de operação do biopoder (Michel FOUCAULT, 2008). O biopoder pode ser compreendido como um modo de exercer o poder que permite o controle de populações inteiras, através do pretexto de proteção e produção de modos de vida. O biopoder não atua sob um único local ou sob um único tipo de indivíduo. Ao contrário, ele age em uma rede complexa que atua por meio de discursos cotidianos, das regras e normas sociais, e sobre os sistemas perceptivos e de pensamentos humanos (William Siqueira PERES; Lívia Gonsalves TOLEDO, 2011). No âmbito das relações familiares, esse dispositivo é responsável pela regulação e disciplinarização das relações, de modo que a família nuclear heterossexual seja considerada a normal, a correta e a forma saudável de constituir uma família.

Para Foucault (1996), em função do poder não estar localizado em nenhum ponto específico da estrutura social, não é possível nos colocarmos fora ou não sermos atravessados por ele, não sendo diferente com a família. Nesse contexto, a família burguesa, a qual - dentre o seu código moral - valoriza a intimidade e o espaço doméstico, vê, com a consolidação do dispositivo do biopoder, desaparecerem as condições para que as questões do corpo e da sexualidade fiquem restritas ao espaço privado das moradias. Isto equivale a dizer que "a família, que se pretendia fechada, encontra-se agora sitiada pelos agentes do biopoder dispostos ao seu redor, querendo conhecer suas práticas e seus costumes, para então oferecer parâmetros do que pode ser considerado normal ou patológico no âmbito familiar" (Paulo Roberto CARVALHO; Sônia Regina Vargas MANSANO, 2017, p. 269).

Demarcadas estas questões a respeito dos efeitos da intervenção normalizadora do biopoder nas famílias e na construção das mulheres nesse contexto, bem como ancorados no reconhecimento da complexidade das relações que se estabelecem a partir do encarceramento masculino, este estudo de caráter qualitativo tem por objetivo discutir qual o modelo de família que é produzido nos discursos e práticas de mulheres que têm relações afetivas e/ou sexuais com homens que estão em situação de prisão. Ademais, busca contribuir para o campo dos estudos de gênero, na medida em que se propõe a estudar as construções de família e de feminilidade em um contexto de vulnerabilidade ainda pouco estudado, que é o contexto prisional.

\section{Metodologia}

Este estudo é decorrente de uma pesquisa de doutorado que teve por objetivo conhecer, a partir de uma abordagem de gênero, os significados atribuídos à paternidade por homens privados de liberdade. O procedimento de coleta informações contou com dois momentos distintos: entrevistas semiestruturadas com pais que estavam em situação de prisão e observações participantes com 
as mulheres que levavam os filhos para a visitação. Todas as observações foram registradas em um diário de campo. É no terreno das reflexões provenientes desse segundo momento que este trabalho se desenrola.

A aproximação das mães que levam seus filhos para visitação partiu do reconhecimento de que a paternidade também se constrói na relação estabelecida entre mãe, pai e filhos, não sendo uma entidade fixa e estática. Assim, escutar o que essas mulheres tinham a dizer era uma forma de compreender os modelos socialmente consolidados do que seriam os papéis de pai e mãe na família, bem como contribuir para a discussão do próprio conceito de família.

A pesquisa foi realizada em uma instituição prisional masculina, localizada no estado do Rio Grande do Sul e que possui um contingente de mais de quatro mil homens. No ano de 2016 , mais de 250 mil visitas aconteceram nas dependências da instituição. Deste total, $87 \%$ foram de mulheres, na maioria mães e companheiras dos indivíduos privados de liberdade (SUPERINTENDÊNCIA DOS SERVIÇOS PENITENCIÁRIOS, 2016). Cumpre destacar que a administração desta casa prisional é feita pela Polícia Militar do estado, diferentemente das demais instituições prisionais, cuja gerência se dá pela Superintendência dos Serviços Penitenciários. Assim sendo, a segurança dos apenados que lá se encontram, bem como a realização dos procedimentos de revista e de atendimento aos visitantes, é realizada por profissionais da Polícia Militar e não por agentes penitenciários.

A coleta de informações foi realizada por uma profissional formada em Psicologia e se deu no período de setembro a dezembro de 2015. A coleta compreendeu observações participantes na Sala de Visitas, local onde os familiares passam pelos procedimentos de segurança e revista antes de ingressar na instituição, e também nas festas de Dia das Crianças e de Natal, organizadas pela direção da Casa Prisional e direcionadas aos familiares dos detentos. As visitas ocorrem todas as terças e quartas, e sábados e domingos. As visitas com crianças só acontecem nos finais de semana. Em função do grande número de apenados, os dias de visitas são divididos entre as galerias. Assim, os mesmos presos recebem visitas nas terças e sábados ou quartas e domingos. As crianças entram apenas uma vez por mês.

Quando a visita chega à instituição, ela entra na fila do cadastro, onde apresenta a sua carteirinha de visitante (cada preso pode receber apenas duas visitas de adultos por vez devidamente cadastrados como visitantes; o número de crianças não é limitado). Ali recebe um número referente ao número da sua "sacola" - itens que os familiares levam para os presos. Cada familiar recebe uma lista onde constam todos os itens que podem ser levados, as cores de roupas que podem levar e vestir, a quantidade de dinheiro que podem fornecer ao preso e demais informações. Após deixar a sacola para inspeção, o familiar é chamado para a revista corporal, realizada por meio de um scanner.

Todo esse procedimento - cadastro, revista de sacola e revista corporal - leva um tempo considerável para ser realizado. Esperas de três ou quatro horas não são raras, já que não há um grande número de profissionais trabalhando nesse espaço e todo o procedimento é feito de forma bastante minuciosa. Era nesse momento em que a aproximação das mães que estavam levando seus filhos para a visitação era possibilitada. A abordagem consistia em conhecer a história dessas mulheres, em entender a importância que davam às visitas de crianças e compreender como se sentiam em frequentar o espaço da prisão.

Todas as observações foram relatadas em um diário de campo. O diário de campo pode ser compreendido como um relato ampliado das impressões da pesquisadora a respeito dos contatos de campo. A utilização dos diários tornou possível que as opiniões e sensações subjetivas da pesquisadora fossem incluídas nos dados, tornando-se acessíveis à análise, enriquecendo a pesquisa através deste recurso (Uwe FLICK, 2009; Anne LAPERRIÈRE, 2008). Os resultados são apresentados a partir de trechos retirados do diário de campo, os quais se referem ora às percepções da própria pesquisadora, ora são reproduções das falas das profissionais que atuam na instituição prisional (soldadas) e/ou das mulheres visitantes. Salienta-se que as informações coletadas foram analisadas à luz do feminismo interseccional e dos estudos sobre o Biopoder, de Foucault.

No que tange aos aspectos éticos, este estudo somente foi realizado após aprovação do Comitê de Ética em Pesquisa (CEP) da instituição proponente da pesquisa, por meio de parecer consubstanciado CAEE: 47039315.4.0000.5336. Os nomes aqui citados são fictícios, a fim de preservar a identidade das participantes.

\section{Resultados e discussão}

Em três meses de observações, inúmeras foram as mulheres que aceitaram conversar sobre a rotina imposta pela visitação, expectativas em relação ao relacionamento com o companheiro aprisionado e percepções sobre a visita de crianças naquele espaço. No entanto, as motivações e a implicação de estarem no ambiente carcerário pareciam assumir aspectos bastante particulares para cada uma delas, tal como o relato a seguir busca ilustrar: 
As mulheres chegam muito cedo, muitas estão na fila já de madrugada, para passar o dia com seu filho/marido/irmão. Muitas precisam jogar fora alguma comida que fizeram, ou por conter algo que não é permitido (como carne com osso, bolo ou pão com cobertura, frutas cítricas etc.) ou por ser de um tamanho maior que o indicado. Muitas mulheres têm uma expressão cansada e sofrida, principalmente aquelas que estão indo visitar o filho e que já têm uma certa idade. Em contraste com elas, meninas muito novas, cheias de energia esperam sua vez de entrar. Elas conversam umas com as outras, exibem cabelos cuidadosamente alisados, maquiagem pesada, calças muito justas que deixam evidente a calcinha minúscula que vestem. Dois extremos separados pela vontade de estar ou não ali: enquanto umas demonstram seu incômodo e cansaço em estar nesta situação, outras parecem exibir com orgulho a condição de mulher de encarcerado (Diário de Campo, 2015).

No que tange às mulheres que visitam seus companheiros na prisão, encontramos tanto aquelas que já possuíam um relacionamento com aquele homem antes do aprisionamento e, portanto, o acompanham desde o início do cumprimento da pena, como aquelas que conheceram o seu parceiro na própria instituição prisional. Nesse contexto, não são raras as que optam por largar seus empregos para se dedicarem integralmente às visitas, ou que assumem a administração de seus negócios ilegais e/ou que decidem engravidar daquele homem mesmo que ele ainda tenha muitos anos de pena a cumprir.

Conforme já mencionado, a possibilidade de gerar um filho deste homem que está em situação de prisão é facilitada pela visita íntima. No caso da instituição onde esta pesquisa foi realizada, devido à superlotação, não há um espaço específico para que tais visitas aconteçam, assim como não há um controle de frequência por parte da administração, sendo a ocorrência dos encontros realizada nas próprias celas e a organização comandada pelos próprios presos. De acordo com os profissionais da casa prisional, ter encontros íntimos garante ao preso certo status perante os demais.

Tu já viu como elas saem daqui no final do dia? Saem com um monte de chupão do pescoço que é uma forma dos homens 'marcarem' a sua visita, e de cabelo molhado que é uma determinação deles também porque isso indica que eles transaram (Bárbara - soldada).

Podemos conjecturar que as "marcações" feitas nas mulheres pelos apenados têm por objetivo demarcar que tipo de masculinidade pode ser encontrada no espaço da prisão, que é aquela pautada na força, na virilidade e na vida sexual ativa. Estas questões se tornam relevantes em um contexto em que a privação de liberdade, de bens e serviços, de autonomia e de segurança são experenciadas como um desafio para os homens presos, já que o contexto cultural determina que o ideal hegemônico é aquele em que os homens devam ser autônomos e viris (Thomas UGELVIK, 2014).

Ao longo do processo de coleta de informações, inúmeras foram as histórias de mulheres que engravidaram quando o marido já estava cerceado de liberdade. No linguajar da cadeia, estes filhos são chamados de "cuiudos" e sua concepção é contada com orgulho tanto pelas mães quanto pelos pais, uma vez que parecem ser vistos como uma importante forma de resistência frente ao processo assujeitador do cárcere. Uma das mães, ao falar sobre uma das filhas geradas na prisão, diz: "quando a minha menina come de tudo, nunca passa mal com nada, devora o que vem pela frente, meu marido sempre comenta 'ela é cuiuda, né amor?!'” [risos] (Sônia Visitante).

Longe de representar uma dificuldade, a decisão por ter um filho com um homem preso pareceu se configurar, para algumas mulheres, como uma tentativa de consolidação da família nuclear desejada, uma vez que, dificilmente - em função do encarceramento e da situação de dependência material/financeira estabelecida -, aquele homem irá abandoná-la. Considerando que muitas dessas mulheres possuem históricos consideráveis de abandono, manter um relacionamento com um homem que está privado de liberdade pode dar uma sensação de segurança proporcionada também pela suposta convicção de fidelidade. Bassani (2011), em um estudo com mulheres que iam visitar seus companheiros na prisão, aponta que, de fato, para muitas delas o cárcere interferiu no relacionamento de modo positivo, uma vez que fez com quepara elas - este evoluísse com mais rapidez e se tornasse mais estável.

Sarti (1994), ao descrever características das famílias de grupos populares, menciona que os lugares ocupados por homens e mulheres nestas famílias se definem a partir de uma estrutura hierárquica de relações em que a figura do homem representa a autoridade moral. Sendo assim, mesmo nos casos em que a mulher assume sozinha a responsabilidade pelo cuidado e sustento da casa, elas seguem designando, em algum nível, um "chefe" masculino. Isto significa dizer que o papel da mulher nessas famílias se dá dentro de uma estrutura em que o homem é fundamental para a própria concepção do que é a família. Assim sendo, sua "presença" é requisitada mesmo quando ele está ausente.

A partir deste entendimento, podemos conjecturar que, em função da ausência ocasionada pela privação de liberdade ser diferente daquela decorrente de um abandono, uma vez que se 
trata de uma ausência situada, ou seja, as mulheres sabem onde seu companheiro está, a "presença" daquele homem na família assume uma importância ainda maior. Tratando sobre grupos populares, Sarti (1994) vai mencionar que o projeto do casamento não é dissociado da crença de que a constituição de uma família só se dá verdadeiramente a partir do nascimento dos filhos. É neste sentido que entendemos que há, dentro da prisão, uma organização social que retira elementos discursivos da sociedade mais ampla e os reconfigura.

A respeito disto, Rod EARLE (2012) - em um estudo realizado com homens privados de liberdade em uma prisão inglesa - menciona a permanência e a reprodução do mito relacionado à singularidade e à solidez da família nuclear frente aos demais modelos familiares. Mesmo quando as histórias de vida e a realidade familiar dos homens entrevistados eram marcadas por rupturas, violência ou abandono, permanecia em seus discursos a idealização de relações simétricas e de intimidade quando falavam sobre sua família.

Esta situação ilustra a ideia de Bourdieu (2008) de que a família, em sua definição legítima, é um privilégio que foi instituído como norma universal. O autor chama a atenção para o fato de que a naturalização do modelo familiar nuclear - tido como natural - não leva em consideração que, para que esta realidade que chamamos de família seja possível, é preciso que diversas condições sociais se encontrem reunidas. Condições estas que não são universais e tampouco são distribuídas de maneira homogênea, engendrando uma tensão entre o ideal igualitário e a realidade da diferença (Claudia FONSECA, 1999).

Esta questão se torna especialmente relevante ao tomarmos como base a realidade social da grande maioria das famílias que possui algum ente encarcerado. Uma realidade marcada pela privação econômica, escassez de acesso a serviços sociais básicos, além de frequentes históricos de violência e abandono. De acordo com Foucault (2004), a extensão do sistema carcerário se dá para além da estrutura física da prisão, já que as ferramentas de normalização estão presentes em outros campos da sociedade, sendo essa a tese central da lógica do biopoder.

À luz deste posicionamento, consideramos o biopoder como uma instrumentalidade que vai se somar à disciplina. Nesse sentido, o poder circula e funciona produzindo o desejo de ter, ou seja, representando um poder que acumula, não sendo repressivo ou coercitivo. É neste panorama que situamos a decisão dessas mulheres em ter um filho com homem em situação de prisão como um reflexo desse efeito de desejo produzido pelo biopoder (FOUCAULT, 2008).

Isto porque esta situação parece refletir a busca dessas mulheres por enquadrarem-se na norma, por constituírem uma família tida como "natural", em que os lugares de pai e mãe são bem definidos e a solidez das relações afetivas se dá a partir da prole. Ademais, num universo simbólico em que é a maternidade que faz da mulher ser efetivamente mulher, ter filhos é superar a condição de ser um ser humano incompleto e inacabado (BOURDIEU, 2008; SARTI, 1994).

Tendo por base o conceito de poder disciplinar, situamos a prisão como uma instituição que busca adestrar, hierarquizar e diferenciar os indivíduos com o objetivo da normalização das condutas (FOUCAULT, 2004; Thamy POGREBINSCHI, 2004). É preciso ressaltar que, muito embora seja evidente que o encarceramento seja um produto da atuação do poder disciplinar, o impacto deste poder não se dá somente naqueles que estão cerceados de liberdade. Ao contrário, os familiares, ainda que estejam "livres", também ficam submetidos àquele poder, isto é, ele repercute sobre eles de modo que também se sintam, de certa forma, presos.

As mulheres dos apenados, nesse contexto, ficam sujeitas a diversos mecanismos de controle como de gênero via o ideal da família nuclear burguesa (GUIMARÃES et al., 2006). Muitas delas acabam sendo controladas fora da prisão por seus companheiros que estão dentro da instituição, uma vez que estes mantêm o poder disciplinar da sociedade patriarcal. O controle, então, é exercido a partir de outros homens que possuem a função de vigiá-las ou mesmo pela interiorização das normas do que seria uma família desejada pelas próprias mulheres.

Frente à complexidade envolvida na trama que liga uma mulher livre a um homem preso (BASSANI, 2011), é preciso irmos além de uma suposição que posicione estas mulheres num papel de submissão. Embora seja evidente que estas mulheres sejam penalizadas pelo acúmulo de responsabilidades que abarca, além dos cuidados domésticos e com os filhos, a provisão financeira da família e o acompanhamento do processo penal do parceiro, quando refletimos sobre a subjetividade dessas "mulheres de bandidos" - termo nativo e que foi apropriado pela literatura ao se referir às mulheres que têm companheiros criminosos ou que estão presos (BARCINSKI; LERMEN; Cristiane CAMPANI; Bibiana ALTENBERND, 2014; Alba ZALUAR, 1993) -, é possível observarmos formas simultâneas de submissão e de empoderamento. Submissão na medida em que tomam para si a responsabilidade pela manutenção dos vínculos afetivos de um modelo familiar idealizado e empoderamento quando se posicionam ativamente frente a companheiros/sujeitos dependentes e incapazes de sobreviver à pena de prisão sem os seus cuidados. A fala a seguir é ilustrativa nesse sentido:

Eu não aguento mais essa vida. Porque se tu for ver, o cansaço não se resume só ao dia da visita, porque no dia anterior tenho que preparar tudo que vou trazer. E é muito gasto, né? Mas 
não tem como... a comida daqui é como se fosse ração pra porco, a gente tem que trazer pra eles (Geci - visitante).

Como já mencionado, a agência historicamente conferida às mulheres se restringe ao espaço privado do lar, ao desempenharem as tarefas de cuidado da casa e dos filhos. No entanto, trata-se de uma agência que é invisibilizada e pouco valorizada na esfera pública. Além disso, se considerarmos que, em grande medida, as famílias chefiadas por mulheres provenientes de grupos populares enfrentam dificuldades importantes devido a diferenças na forma de inserção da mulher no mercado de trabalho (SARTI, 1994), tornar-se e ser identificada como "mulher de bandido" pode se constituir como algo que conceda protagonismo à constituição identitária dessas mulheres. O relato da profissional a seguir traz contribuições nesse sentido:

Um dia chegou aqui pra fazer cadastro pra visitação uma menina nova, loira, bem vestida, muito bonita. Perguntei se os pais dela sabiam que ela estava aqui e ela disse que não, que eles achavam que ela tava na aula de inglês. Ai eu olhei pra ela e disse 'olha aquelas mulheres ali, um dia elas já foram bonitas e novas como tu e agora olha como elas tão, olha o que a prisão fez com elas... não volta mais aqui, não escolhe essa vida pra ti'. Mas ela me disse com orgulho que era mulher de 'plantão' [presos que detêm o poder e são os responsáveis pela organização e segurança de determinada galeria], como se isso fosse grande coisa... (Bárbara - soldada).

Sob essa perspectiva, é possível conjecturarmos que as motivações dessas mulheres que sustentam um relacionamento com um homem preso são contraditórias e ambivalentes, uma vez que envolvem, de um lado, o desejo por esse homem, bem como os supostos ganhos simbólicos dessa relação pela aderência ao ideal e, por outro, o sofrimento de suportarem as violações impostas pelas instituições prisionais e as dificuldades cotidianas decorrentes do aprisionamento (BARCINSKI; LERMEN; CAMPANI; ALTENBERND, 2014; BASSANI, 2011). Uma destas dificuldades pode ser visualizada no recorte a seguir, na medida em que o trabalho e as obrigações cotidianas da visitante sofrem influência direta da rotina imposta pela visitação na instituição prisional:

Agora eu tô trabalhando na lanchonete que uma amiga minha é a dona. Ela me deu esse emprego pra me dar uma força, sabe? Hoje era dia de trabalhar, mas eu tô muito cansada, essa rotina de visitas me deixa exausta porque eu acordo muito cedo pra vir pra cá e sempre espero muito tempo pra entrar na cadeia. Eu trabalho à noite, né, daí, às vezes, eu até tento sair mais cedo daqui pra poder descansar um pouco antes de ir, problema é que quando tô lá dentro, ele não me deixa sair, quer que eu fique com ele e aí eu acabo ficando (Caroline - visitante).

Evidentemente, nem todas as mulheres que sustentam um relacionamento com um homem preso o fazem por livre e espontânea vontade. Isso porque muitas são controladas e vigiadas por aquele homem, o que oblitera a possibilidade de terminarem o relacionamento. Por outro lado, ainda que com receio e preocupação por sentirem-se controladas, muitas mulheres lisonjeiam-se de toda a atenção dispensada pelo companheiro, uma vez que este controle reafirmaria a posição que ocupam de objeto de desejo na vida do companheiro (GUIMARÃES et al., 2006).

O fato é que, mesmo em uma realidade em que a rotina imposta pela visitação as deixa fatigadas e as vincule a trabalhos mal remunerados em tempo parcial ou intermitente, de modo a dar conta de estar presente em todas as visitas, são as mulheres que assumem a autonomia da manutenção dessa relação. São elas, afinal, que decidem se vão visitar, o que vão levar a estes homens, se vão levar os filhos para vê-los, situando este homem numa posição passiva, de quem somente espera. O recorte a seguir vem ao encontro dessa afirmação:

Pra ti ver como ele foi burro em ter se metido nisso [o marido havia sido preso por participação em um assalto] que não ganhou um centavo com isso. Aí agora eu tenho que ficar vindo aqui, mas eu já disse pra ele que eu só tô vindo porque foi a primeira vez que isso aconteceu, vou seguir firme com ele, ser forte, dar todo o suporte, mas se houver uma segunda vez eu não pretendo passar por isso tudo de novo. [...] $E$ eu já disse pra ele também que não vou ficar trazendo o Bruno [filho do casal de 1 ano e 4 meses] aqui porque eu trouxe uma vez e ele saiu todo agressivo, xingando, tentando me bater, dando tapa, nem pensar... (Vitória - visitante).

O protagonismo assumido por algumas mulheres na relação com seu companheiro encarcerado também pôde ser percebido na relação estabelecida com a pesquisadora. Inicialmente, a ideia pretendida era a de que os nomes dos possíveis homens a serem entrevistados no segundo momento da pesquisa partissem da indicação das próprias companheiras. No entanto, após inúmeros questionamentos que buscavam identificar que tipo de acesso a pesquisadora teria às galerias, o quão irrestrito seria este acesso e quanto tempo ficaria com os homens, nenhuma das companheiras quis que seu companheiro fosse sujeito do estudo. A recusa dessas mulheres em indicar nomes - possivelmente por identificarem a pesquisadora como sendo uma ameaça a esta relação - também pode ser pensada sob a ótica do protagonismo.

Aludirmos à possibilidade do empoderamento feminino em contextos de sacrifício e resignação para as mulheres não significa corroborar ou legitimar as formas tradicionais de subjugação feminina. Ao contrário, reforçar que, muitas vezes, o empoderamento das mulheres se 
dá justamente através do posicionamento vitimizado delas, aponta para as formas limitadas de protagonismo feminino socialmente legitimado (BARCINSKI; CAPRA-RAMOS; WEBER; DARTORA, 2013).

No caso das mulheres que possuem envolvimento com homens em situação de prisão - em sua grande maioria vindas de classes populares - para além das opressões vividas pelo fato de ser mulher, há também a questão da baixa escolaridade, das oportunidades de trabalho que não contribuem para o desenvolvimento de sua autonomia e, em muitos casos, a discriminação racial, visto que muitas são negras ou pardas. É neste contexto marcado por diversos atravessamentos de opressão que se apresentam de modo simultâneo com a questão de gênero, que o protagonismo dessas mulheres pode ser visualizado a partir da prerrogativa da resistência.

\section{Considerações finais}

Este estudo teve por objetivo discutir qual o modelo de família que é produzido nos discursos e práticas de mulheres que têm relações afetivas ou sexuais com homens que estão em situação de prisão, a partir de uma análise do feminismo interseccional e do estudo do biopoder. Por meio de observações participantes com mulheres que visitam seus familiares e do deslocamento das questões de gênero, raça e classe para um primeiro plano de análise, foi possível identificar que o modelo de família produzido ainda é sustentado pelo modelo hegemônico tradicional, que entende a família nuclear como a representação do sucesso e solidez familiar.

Ainda que a reprodução deste modelo possa ser vista como a manutenção de relações familiares estereotipadas, que situam as mulheres em posição de subalternidade, é preciso considerar que - paradoxalmente - manter um relacionamento com um homem que está encarcerado pode ser empoderador para muitas mulheres. Isto porque assumem para si a autonomia e o poder sobre a manutenção ou não da relação e da visitação, posicionando aquele homem em um lugar de dependência. Ademais, considerando que a grande maioria dessas mulheres é negra, proveniente de grupos populares e assume sozinha a manutenção da casa e cuidado com os filhos, conjecturamos que se reconhecer e ser reconhecida como mulher de bandido pode trazer ganhos simbólicos para essas mulheres.

Evidentemente, as questões aqui levantadas não objetivam argumentar em prol das benesses envolvidas em se ter um relacionamento com um homem privado de liberdade. Buscam, por outro lado, apontar para o caráter paradoxal envolvido nessa situação, em que a prisão do companheiro pode proporcionar certa "liberdade" para as mulheres no que se refere a aspectos de autonomia, agência dentro da família e ganhos identitários.

Isso porque há um deslocamento do lugar em que são vistas como subalternas, mulheres sozinhas, vítimas do abandono, para outro que as reconhece como "guerreiras", como alguém que, enfrentando todas as adversidades impostas pelo aprisionamento de um familiar, se mantêm fortes e com autonomia para escolher de que forma irão manter esse relacionamento. Tal situação aponta para a precariedade de uma sociedade que se vê incapaz de produzir e possibilitar os meios adequados para que as mulheres sejam protagonistas de sua própria história, fazendo com que relacionamentos que se desenvolvem em um ambiente segregado e marcado por diversas privações sejam capazes, em muitos casos, de produzir efeitos mais positivos do que aqueles que acontecem em outros ambientes que não o da prisão.

Essa situação demonstra não só as poucas possibilidades legitimadas socialmente de empoderamento feminino, como contesta o fato de que a prisão é somente um lugar à margem da sociedade. A respeito disto, argumentamos que o cárcere não está à margem, ele é a sociedade reproduzida em seu espaço, com toda a sua contradição, comportamentos estereotipados e busca por ideais familiares socialmente validados. Nesse panorama, em que os agentes do biopoder com suas prescrições pontuam o que é certo, saudável e adequado no ambiente familiar, as mulheres aqui descritas buscam, por meio do relacionamento com aquele homem privado de liberdade, ascender ao código moral da família nuclear burguesa, em um contexto marcado pela precarização dos corpos dos indivíduos que têm a sua trajetória assinalada pelo cárcere.

Em suma, foi possível identificar que os ideais de família, representados pela suposta solidez da família nuclear, operam através da reprodução de certas normas e papéis que as mulheres acabam assumindo e que possuem, inclusive, certo caráter empoderador. Empoderador porque, como já mencionado, possibilitam certa agência e autonomia num contexto em que diversas formas de opressão se intersectam com a questão de gênero, tais como raça e classe.

Diante do exposto, entendemos que este estudo contribui para os estudos de gênero e da sexualidade na medida em que tensiona a ideia amplamente mencionada pela agenda feminista de que a instituição familiar ałua sempre como lócus de controle na vida das mulheres. Os resultados aqui apresentados apontam que, apesar das inúmeras prescrições normativas que ainda regem as famílias em suas diferentes configurações, muitas mulheres conseguem resistir e subverter as imposições de obediência e de submissão reguladas pela ordem patriarcal.

Vale mencionar, contudo, que a resistência dessas mulheres e o tensionamento nas relações de poder aqui descritas são circunscritas ao nível micro da relação. Isso equivale a dizer que, 
embora o estudo aponte para um suposto empoderamento dessas mulheres, já que os homens estão presos e o controle de uma parte da relação é exercido por elas, isto não isenta o fato de que as mulheres continuam se sujeitando ao patriarcado e às relações assimétricas de gênero que são estruturais.

A importância do estudo está também na atualização dos conceitos de interseccionalidade, biopoder e família, almejando mostrar como eles operam no contexto específico da prisão. Além disso, os resultados aqui encontrados apontam para a diversidade de formas de ser mulher em famílias provenientes de um contexto marcado pelas desigualdades de classe, de raça e de privação de liberdade, não havendo uma única forma de vivenciar a interseção desses marcadores.

Como limitação do estudo, salientamos a dificuldade que algumas mulheres possuíam em falar sobre suas histórias. Esse receio em compartilhar com a pesquisadora suas impressões e aspectos da sua rotina cotidiana pode ter sido motivado pelo temor e fantasia de que os depoimentos pudessem incriminar ou prejudicar o marido, uma vez que tais receios são característicos em pesquisas no ambiente prisional.

\section{Referências}

BADINTER, Elisabeth. Um amor conquistado - O mito do amor materno. Tradução de Waltensir Dutra. Rio de Janeiro: Nova Fronteira, 1985.

BARCINSKI, Mariana; CAPRA-RAMOS, Carine; WEBER, João L. A.; DARTORA, Tamires. "O Marianismo e a vitimização de mulheres encarceradas: formas alternativas de exercício do poder feminino". Ex aequo, Vila Franca de Xira, n. 28, p. 87-100, 2013.

BARCINSKI, Mariana; LERMEN, Helena Salgueiro; CAMPANI, Cristiane; ALTENBERND, Bibiana. "Guerreiras do cárcere: uma rede virtual de apoio aos familiares de pessoas privadas de liberdade". Temas em Psicologia, Ribeirão Preto, v. 22, n. 4, p. 929-940, dez. 2014.

BASSANI, Fernanda. "Amor bandido: cartografia da mulher no universo prisional masculino". Dilemas: Revista de Estudos de Conflito e Controle Social, v. 4, n. 2, p. 261-280, abr. 2011.

BOURDIEU, Pierre. Razões práticas: sobre a teoria da ação. Tradução de Mariza Corrêa. Campinas: Papirus, 2008.

BRASIL. Lei de Execução Penal, de 11 de julho de 1984. Disponível em http://www.planalto.gov.br/ ccivil_03/leis/l7210.htm. Acesso em 10/06/2017.

BRASIL. Resolução $n^{\circ}$ 01, de 30 de março de 1999. Disponível em http://www.justica.gov.br/seusdireitos/politica-penal/cnpcp-1/resolucoes/resolucoes-arquivos-pdf-de-1980-a-2015/resolucao-no01-de-30-de-marco-de-1999.pdf. Acesso em 17/10/2017.

BRASIL. Mulheres Encarceradas: Consolidação dos Dados Fornecidos pelas Unidades da Federação. Brasília: Ministério da Justiça. Departamento Penitenciário Nacional, 2008.

CARVALHO, Paulo Roberto; MANSANO, Sônia Regina Vargas. "Família e biopolítica: a destruição da intimidade nas sociedades contemporâneas". Psicologia em Estudo, v. 22, n. 2, p. 265-276, 2017.

CROCHIK, José Leon. "Preconceito, indivíduo e sociedade". Temas em Psicologia, Ribeirão Preto, v. 3, n. 4, p. 47-70, dez. 1996.

CÚNICO, Sabrina Daiana; ARPINI, Dorian Mônica. "Família e monoparentalidade feminina sob a ótica de mulheres chefes de família". Aletheia, Canoas, n. 43-44, p. 37-49, ago. 2014.

EARLE, Rod. “'Who's the Daddy?' - Ideas about fathers from a Young men's prison”. The Howard Journal of Criminal Justice, v. 51, n. 4, p. 387-399, set. 2012.

FLICK, Uwe. Introdução à pesquisa qualitativa. Tradução de Joice Elias Costa. Porto Alegre: Artmed, 2009.

FONSECA, Claudia. "O abandono da razão: a descolonização dos discursos sobre a infância e a família". In: SOUSA, Edson Luiz André de (Org.). Psicanálise e Colonização: leituras do sintoma social no Brasil. Porto Alegre: Artes e Ofícios, 1999. p. 255-274.

FOUCAULT, Michel. Microfísica do poder. Tradução de Roberto Machado. Rio de Janeiro: Edições Graal, 1996. 
FOUCAULT, Michel. Vigiar e Punir: Nascimento da prisão. Tradução de Raquel Ramalhete. Petrópolis: Vozes, 2004.

FOUCAULT, Michel. Nascimento da biopolítica. Tradução de Eduardo Brandão. São Paulo: Martins Fontes, 2008.

GUIMARÃES, Cristian Fabiano et al. "Homens apenados e mulheres presas: estudo sobre mulheres de presos". Psicologia e Sociedade, Porto Alegre, v. 18, n. 3, p. 48-54, dez. 2006.

LAPERRIÈRE, Anne. "Os critérios de cientificidade dos métodos qualitativos". In: POUPART, Jean et al. (Orgs.). A pesquisa qualitativa: Enfoques epistemológicos e metodológicos. Petrópolis: Vozes, 2008. p. $410-435$.

LERMEN, Helena Salgueiro. Amor e maternidade no cárcere: mulheres que têm filhos com homens encarcerados. 2015. Dissertação (Mestrado em Psicologia) - Programa de Pós-Graduação em Psicologia, Faculdade de Psicologia da PUCRS, Porto Alegre, RS, Brasil.

LYRA, Jorge et al. "Homens e cuidado: uma outra família?". In: ACOSTA, Ana Rojas; VITALE, Maria Amalia Faller (Org.). Famílias: redes, laços e políticas públicas. São Paulo: Cortez, 2008. p. 79-91.

NARVAZ, Martha Giudice; KOLLER, Silvia Helena. "A concepção de família de uma mulher-mãe de vítimas de incesto". Psicologia: Reflexão e Crítica, Porto Alegre, v. 19, n. 3, p. 395-406, 2006 a.

NARVAZ, Martha Giudice; KOLLER, Silvia Helena. "Famílias e patriarcado: da prescrição normativa à subversão criativa". Psicologia \& Sociedade, Porto Alegre, v. 8, n. 1, p. 49-55, abr. $2006 \mathrm{~b}$.

OLIVEIRA, João Manuel. "Os feminismos habitam espaços hifenizados - a localização e interseccionalidade dos saberes feministas". Ex aequo, Vila Franca de Xira, n. 22, p. 25-39, 2010.

PERES, Vannuzia Leal Andrade. Família de crianças em situação de rua: Modos de vida, relacionamento familiar e práticas educativas. 1997. Dissertação (Mestrado em Educação) Programa de Pós-Graduação em Educação, Faculdade de Educação da UFG, Goiânia, GO, Brasil.

PERES, Vannuzia Leal Andrade. "Concepções de família em população de periferia urbana". In: SOUSA, Sônia M. Gomes (Org.). Infância, Adolescência e Família. Goiânia: Cânone Editorial, 2001. p. 217-230.

PERES, William Siqueira; TOLEDO, Lívia Gonsalves. "Dissidências existenciais de gênero: resistências e enfrentamentos ao biopoder”. Psicologia Política, São Paulo, v. 11, n. 22, p. 261-277, dez. 2011.

PINTO, Rosa Maria Ferreira et al. "Condição feminina de mulheres chefes de família em situação de vulnerabilidade social”. Serviço Social \& Sociedade, São Paulo, n. 105, p. 167-179, mar. 2011.

PISCITELLI, Adriana. "Interseccionalidades, categorias de articulação e experiências de migrantes brasileiras". Sociedade e Cultura, v. 11, n. 2, p. 263-274, jul./dez. 2008.

POGREBINSCHI, Thamy. "Foucault, para além do poder disciplinar e do biopoder". Lua Nova: Revista de Cultura e Política, n. 63, p. 179-201, 2004.

SARTI, Cynthia A. "A família como ordem moral". Cadernos de pesquisa, São Paulo, n. 91, p. 46-53, 1994.

SUPERINTENDÊNCIA DOS SERVIÇOS PENITENCIÁRIOS. (2016). Relatório Estatístico de Visitas. Disponível em http://www.susepe.rs.gov.br. Acesso em 10/11/2017.

STOLCKE, Verena. "¿Qué tiene que ver el género con el parentesco?". Cadernos de Pesquisa, São Paulo, v. 44, n. 151, p. 176-189, mar. 2014.

UGELVIK, Thomas. "Paternal pains of imprisonment: Incarcerated fathers, ethnic minority masculinity and resistance narratives". Punishment \& Society, v. 16, n. 2, p. 152-168, 2014.

ZALUAR, Alba. "Mulher de Bandido: crônica de uma cidade menos musical". Revista Estudos Feministas, Florianópolis, v. 1, n. 1, p. 135-142, jan. 1993.

Sabrina Daiana Cúnico (sabrinacunico@feevale.br/sabrinacunico@yahoo.com.br)é psicóloga, mestre em Psicologia pela Universidade Federal de Santa Maria (UFSM), doutora em 
Psicologia pela Pontifícia Universidade Católica do Rio Grande do Sul (PUCRS), pós-doutoranda em Psicologia pela Universidade Federal do Rio Grande do Sul (UFRGS) e professora do curso de Psicologia da Universidade Feevale.

Marlene Neves Strey (nevesstrey@gmail.com) é psicóloga, mestre em Psicologia pela Pontifícia Universidade Católica do Rio Grande do Sul (PUCRS), doutora em Psicologia pela Universidad Autónoma de Madrid (UAM). Professora aposentada do Programa de Pós-Graduação em Psicologia da Pontifícia Universidade Católica do Rio Grande do Sul (PUCRS).

Angelo Brandelli Costa (angelo.costa@pucrs.br/angelobrandellicosta@gmail.com) é psicólogo, mestre em Psicologia Social e Institucional pela Universidade Federal do Rio Grande do Sul (UFRGS), doutor em Psicologia pela Universidade Federal do Rio Grande do Sul (UFRGS). Professor de Psicologia Social do Programa de Pós-Graduação em Psicologia da Pontifícia Universidade Católica do Rio Grande do Sul (PUCRS) e coordenador do Grupo de Pesquisa Preconceito, Vulnerabilidade e Processos Psicossociais.

\section{COMO CITAR ESSE ARTIGO DE ACORDO COM AS NORMAS DA REVISTA}

CÚNICO, Sabrina Daiana; STREY, Marlene Neves; COSTA, Angelo Brandelli. "Quem está no comando? Mulher de bandido e os paradoxos da submissão". Revista Estudos Feministas, Florianópolis, v. 27, n. 2, e54483, 2019.

\section{CONTRIBUIÇÃO DE AUTORIA}

Sabrina Daiana Cúnico - Concepção, coleta e análise de dados, elaboração do manuscrito, redação, realização das entrevistas e discussão dos resultados

Marlene Neves Strey - Redação e discussão de resultados

Angelo Brandelli Costa - Concepção, elaboração do manuscrito e redação, discussão dos resultados

\section{FINANCIAMENTO}

Coordenação de Aperfeiçoamento de Pessoal de Nível Superior (CAPES), através de bolsa de doutorado concedida à primeira autora.

\section{CONSENTIMENTO DE USO DE IMAGEM}

Não se aplica

APROVAÇÃO DE COMITÊ DE ÉTICA EM PESQUISA

Aprovação de comitê de ética em pesquisa: Aprovação no CEP da PUCRS, através do CAEE: 47039315.4.0000.5336

\section{CONFLITO DE INTERESSES}

Não se aplica

\section{LICENÇA DE USO}

Este artigo está licenciado sob a Licença Creative Commons CC-BY Internacional. Com essa licença você pode compartilhar, adaptar, criar para qualquer fim, desde que atribua a autoria da obra.

\section{HISTÓRICO}

Recebido em 11/12/2017

Reapresentado em 06/09/2018

Reapresentado em 13/09/2018

Aprovado em 18/09/2018 